\title{
Importance of family history in type 2 black South African diabetic patients
}

\author{
R T Erasmus, E Blanco Blanco, A B Okesina, J Mesa Arana, Z Gqweta, T Matsha
}

\begin{abstract}
Objective-To assess the family history of diabetes in type 2 black South African diabetics with emphasis on the parental phenotype.

Design-Prospective case-control study in which family histories were obtained from patients.

Setting-Diabetic clinic of a provincial teaching hospital in the Transkei region of South Africa.

Subjects-A total of 1111 type 2 diabetics attending the diabetic clinic and 687 controls.

Main outcome measures-History of diabetes in parents, siblings, maternal and paternal grandparents, aunts, and uncles. Results-Altogether $27.3 \%$ of diabetic subjects had a family history of diabetes compared with $8.4 \%$ in the control group $(\mathrm{p}<0.01)$. Among the group with positive family history $82.6 \%$ reported only one diabetic family member, while $17.4 \%$ reported at least two relatives; $6.6 \%$ had a diabetic relative from both maternal and paternal sides, and $87.8 \%$ had first degree relative with diabetes. Among them there was a significant maternal aggregation with $64.7 \%$ of patients having a diabetic mother compared with $27 \%$ who had a diabetic father $(p<0.01)$. No maternal effect was observed among the second and third degree relatives. Patients with positive family history had an earlier onset of diabetes than those without family history $(\mathbf{p}<0.01)$.

Conclusion-These data suggest that type 2 diabetes is heritable in black South African diabetics. It is also likely that maternal influences may play an important part.

(Postgrad Med f 2001;77:323-325)
\end{abstract}

Keywords: diabetes; family history

Department of

Chemical Pathology,

Faculty of Medicine,

University of Transkei,

Private Bag XI,

Umtata, South Africa

R T Erasmus

E Blanco Blanco

A B Okesina

J Mesa Arana

Z Gqweta

T Matsha

Correspondence to:

Professor Erasmus

erasmus@getafix.utr.ac.za

Submitted 8 November 1999 Accepted 20 September 2000 black African diabetics. At a time when twin studies have amply demonstrated the heritability of diabetes mellitus in the rest of the world, it may appear out of time to study family history of diabetes mellitus in black South Africans. Except for a single small study by Omar and Asmal in 1983, the familial nature of the disease has never been established in sub-Saharan Africa. ${ }^{10}$ The former Republic of Transkei is inhabited predominantly by Xhosa speaking people. The prevalence of diabetes has recently been reported to be high in immigrant Xhosas residing in Cape Town, South Africa, which is more than $1000 \mathrm{~km}$ away. ${ }^{11}$ The objective of this study was to assess the frequency of diabetes in family members of diabetic subjects residing in the Transkei region and also to investigate the role of maternal transmission.

\section{Methods}

The study was carried out at Umtata General Hospital. This 1000 bed facility is the major referral centre for the former homeland of Transkei. The diabetic clinic is held once a week and all patients from the peripheral clinic as well as those seen within the hospital are referred to it. All Xhosa diabetics who attended the clinic between January 1996 and June 1998 were interviewed. Data collected included sex, age, and age at onset of diabetes and detailed family history. The control group consists of healthy non-diabetic Xhosa males and females who were recruited from the greater subregion of Umtata district and were part of a larger study to screen for hypertension and diabetes. The majority of our controls underwent an oral glucose tolerance test or a fasting plasma glucose determination to exclude diabetes.

Patients and controls were classified into two main groups for negative and positive family history and the latter were further divided according to the presence of diabetic relatives from either the maternal or paternal sides. Relatives having diabetes were also classified as follows: first degree for parents and siblings, second degree for aunts and uncles, and third degree for grandparents. Patients who could not remember or were ignorant of their relative's diabetes status were excluded from the study. Because of the joint and extended family of the majority of the patients, it was possible by persisting questioning to ascertain the presence or absence of diabetes in family members.

In order to compare the maternal or paternal aggregation of diabetic relatives, 63 cases having only diabetic siblings were excluded from the first degree relative category. 
Table 1 Details of family history of diabetes

\begin{tabular}{lcc}
\hline Family history & No (\%) diabetics & No (\%) controls \\
\hline Negative & $807(72.7)$ & $687(91.6)$ \\
Positive & $304(27.3)$ & $58(8.4)$ \\
Father & $55(4.9)$ & $16(2.3)$ \\
Mother & $132(11.9)$ & $35(5.1)$ \\
Both parents & $17(1.5)$ & - \\
Siblings & $94(8.5)$ & $9(1.3)$ \\
Paternal aunt/uncle & $13(1.2)$ & $1(0.1)$ \\
Maternal aunt/uncle & $19(1.7)$ & $1(0.1)$ \\
Paternal grandparent & $7(0.6)$ & $-2(0.3)$ \\
Maternal grandparent & $11(1.0)$ & 2 \\
\hline
\end{tabular}

STATISTICAL ANALYSIS

Data were entered into a data base file using dBase III program and later imported in EP16 which was used in the final analysis of comparison of the values of means of different variables. Frequencies were expressed as percentages and $\chi^{2}$ analysis was used to compare them; a $\mathrm{p}$ value $<0.05$ was taken as significant.

\section{Results}

There were 1153 diabetics out of which 42 patients were unable to provide a satisfactory answer with respect to their family history of diabetes. This left 1111 cases for the study, of which $71.6 \%$ were females and $28.4 \%$ males with a mean (SD) age of $56.5(11.8)$ years. The control group consisted of 687 subjects $(54.6 \%$ females and $45.4 \%$ males). Controls were similar to diabetics with respect to occupation, urban or rural residence, ethnicity, and age (mean (SD) age of 55.5 (12.4) years, $\mathrm{p}=0.093)$. Both diabetics and controls were Xhosa speaking South African blacks. In all cases males and females were described together because no evidence of sex effect was noted.

Among diabetic subjects the frequency of diabetic relatives was $27.3 \%$ while for the control group it was only $8.4 \%, \mathrm{p}<0.01$ (table 1 ). It is difficult to compare this frequency with the prevalence of diabetes in the general Xhosa population because of limited data.

The validity of the responses was ascertained by inquiring if relatives had izwekile. This term in the Xhosa community identifies the presence of polyuria, polydypsia, and a sweet urine. This was further confirmed by inquiring if their relatives were using an artificial sweetener. A standard policy of the local health authorities is to issue an artificial sweetener only to diabetic patients.

The diabetic patients could be considered to be representative of the population as the clinic used for this study is the only one in the region to which diabetic patients from all health centres are referred.

FREQUENCY OF DIABETIC RELATIVES

Altogether $304(27.3 \%)$ of the diabetic subjects reported at least one diabetic family member. Among the diabetic subjects with positive family history $251(82.6 \%)$ reported one diabetic family member and $53(17.4 \%)$ reported at least two relatives. When classifying these results according to first, second, and third degree status, $267(87.8 \%)$ of patients had first
Table 2 Aggregation of diabetic relatives in the diabetic group

\begin{tabular}{lr}
\hline Relatives & No (\%) \\
\hline First degree relatives & \\
Father & $55(27.0)$ \\
Mother & $132(64.7)$ \\
Both & $17(8.3)$ \\
Subtotal (excludes 63 patients having siblings & \\
$\quad$ only) & $204(100)$ \\
Second degree relatives & $13(40.6)$ \\
Paternal aunt/uncle & $17(53.1)$ \\
Maternal aunt/uncle & $2(6.3)$ \\
Both & $32(100)$ \\
Subtotal & $6(33.3)$ \\
Third degree relatives & $8(44.5)$ \\
Paternal grandparent & $4(22.2)$ \\
Maternal grandparent & $18(100)$ \\
Both & \\
Subtotal &
\end{tabular}

${ }^{\star} \mathrm{p}<0.01$ for maternal $v$ paternal transmission.

Table 3 Family history and age of onset of diabetes

\begin{tabular}{lrl}
\hline Family history of diabetes & No & $\begin{array}{l}\text { Mean (SD) age } \\
\text { at onset of diabetes (years) }\end{array}$ \\
\hline Paternal side & 75 & $44.5(11.3)$ \\
Maternal side & 146 & $44.9(9.7)$ \\
Both & 20 & $44.6(10.0)$ \\
None & 870 & $51.5(11.6)$
\end{tabular}

degree relatives with diabetes, $32(10.5 \%)$ second degree, and 18 (5.9\%) third degree relatives (table 2).

\section{MATERNAL EFFECT}

Twenty $(6.6 \%)$ diabetics with a positive family history had a diabetic relative from both the maternal and paternal side; 75 (31.1\%) reported having a history among paternal relatives and $146(60.6 \%)$ had maternal relatives with diabetes $(\mathrm{p}<0.001)$.

Among index patients, $132(64.7 \%)$ with a first degree relative had a diabetic mother compared with $55(27 \%)$ who had a diabetic father $(p<0.0001)$. However, among second and third degree relatives the maternal effect was not observed (table 2). The control group showed a similar pattern in the distribution of maternal and paternal relatives.

AGE AT DIAGNOSIS OF DIABETES IN INDEX PATIENTS

We observed that those patients with positive family history had an earlier onset of diabetes than those without a family history (mean (SD) $44.7(10.0) v 51.5$ (11.6) years, $\mathrm{p}<0.01)$. This was however irrespective of either maternal or paternal effect (table 3).

\section{Discussion}

With changing lifestyles and increasing urbanisation, the number of black Africans with diabetes mellitus is increasing world wide. ${ }^{11} 12$ The magnitude of the problem of diabetes in black South Africans is unknown but recent reports suggest that there may be a higher prevalence of diabetes among certain population groups such as the Xhosas from Transkei. ${ }^{11}$ Previous reports from Africa have attributed the presence of diabetes to being secondary to siderosis, malnutrition, and pancreatic calcification. However, this has been questioned by Omar and Asmal who in 1983 found a $37 \%$ positive family history among a 
relatively small number of 19 black South African diabetics predominantly of Zulu descent. ${ }^{10}$ Elsewhere from Africa, Mengesha and Abdulkadir reported a significant positive history in first, second, and third degree relatives of Ethiopian diabetics. ${ }^{13}$ This study to our knowledge is one of the largest on black South Africans. The Xhosas represent one of the major population groups of South Africa and are related to the Zulus. We found that $27.3 \%$ of diabetic subjects in our study had a positive family history, a figure that is lower than that reported by Omar and Asmal. ${ }^{10}$ Our study had data on family histories from a non-diabetic group. The finding of significant differences between cases and controls with regards to the family history among their first degree relatives indicate that diabetes in this South African population may be a heritable condition. A possible hypothesis could be attributed to the observation of a high prevalence of low birth weight among the Xhosas. ${ }^{14}$ Low birth weight has been reported to be associated with the subsequent development of diabetes and hypertension and this partly may explain our observations. ${ }^{1516}$ Varying results have been reported in a number of studies from Europe and America. For example in the French CODIAB study of 218 type 2 diabetics, $66 \%$ had at least one diabetic relative. ${ }^{17}$ Cheta et al found that among 300 type 2 patients, 33\% had a diabetic relative while in the Whitehall study $33 \%$ of diabetic cases had a diabetic family member. ${ }^{18} 119$ Though our figures are similar to that reported in the population based Wisconsin study by Klein et al they probably are an underestimate as data on the presence of diabetes among offspring of index patients was not available. ${ }^{20}$

The younger age of onset in offspring of diabetic parents may have been the result of a greater awareness of presenting symptoms. These results are also similar to the CODIAB study as well as that reported by Simpson. ${ }^{717}$ Environmental factors could also have played an important part in late onset diabetics. We were unable to determine if parents of young onset were on average younger than parents of individuals with late onset diabetes as majority of patients could not provide information on the age of their respective parents.

Recent studies suggest that intrauterine environment may have a role in the transmission of type 2 diabetes. ${ }^{21}$ Offspring of Pima Indian women are more likely to develop diabetes if their mothers were diabetic during the pregnancy than if their mothers developed diabetes later in life. We therefore investigated the role of maternal inheritance. We found that $64.7 \%$ had a diabetic mother compared with $27 \%$ who had a diabetic father. These results could not be confirmed by third generation studies, as we were unable to obtain data on the presence of diabetes among the offspring of index cases. Our findings are in agreement with those of Thomas et al who reported that mothers were about twice as likely to have diabetes than fathers. ${ }^{17}$ Similarly Klein et al concluded that there was an excess of cases in mothers of diabetics and stated that this was compatible with both environmental and genetic factors. ${ }^{20}$ In one of the largest studies from Europe, Alcolando and Alcolando also reported that maternal influences seem to have an important role in the inheritance of type 2 diabetes. ${ }^{22}$ However, in contrast to these reports Mitchell et al found no evidence of maternal transmission in a group of Mexican Americans. ${ }^{23}$ One explanation for our observation could be the higher life expectancy among females due to social and ethnic factors. ${ }^{24}$ One can also not reject the hypothesis that patients may have more knowledge of their mother's health status.

In summary we found a strong genetic component in our study. The familial component was more important when the disease was diagnosed at an earlier age. We believe that these results would form the platform for prospective and more detailed studies that would follow up the offspring of diabetic patients.

1 Barnett AH, Eff C, Leslie RDG, et al. Diabetes in identical twins. A study of 200 pairs. Diabetologia 1981;20:87-93.

2 Turner R, Hattersley A, Cook J. Type 2 diabetes: search for primary defects. Ann Intern Med 1992;24:511-16.

3 Hitman GA, McCarthy MI. Genetics of non insulin dependent diabetes mellitus. Baillieres Clin Endocrinol Metab 1991;5:477-93.

4 Newman B, Selby JV, King MC, et al. Concordance for type 30:763-8

5 Permutt MA. Genetics of NIDDM. Diabetes Care 1990;13: 1150-3.

6 Simpson N. Multifactorial inheritance: a possible hypothesis for diabetes. Diabetes 1964;13:462-71.

7 Simpson N. Diabetes in the families of diabetics. Can Med Assoc F 1968;98:427-32.

8 Eriksson J, Fransilla-Kallunski A, Ekstrand A, et al. Early metabolic effects in persons at increased risk for non insulin dependent diabetic mellitus. N Engl F Med 1989;321:33743.

9 Warram JH, Martins BC, Knolewski AS, et al. Slow glucose removal rate and hyperinsulinaemia precede the development of type 2 diabetes in the offspring of diabetic parents. Ann Intern Med 1990;113:909-15.

10 Omar MAK, Asmal AC. Family histories of diabetes mellitus in young African and Indian diabetics. BMF 1983;286: 1786 .

11 Levit NS, Katzenellenbogen JM, Bradshaw D, et al. Prevalence and identification of risk factors for NIDDM in urban Africans in Cape Town, South Africa. Diabetes Care 1993;16:601-7

12 Erasmus RT, Fakeye T, Olukoga AO, et al. Prevalence of diabetes in Nigerians Trans R Soc Trop Hyg 1989;83:417-18.

13 Mengesha B, Abdulkadir J. Heritability of diabetes mellitus in Ethiopian diabetics. E Afr Med f 1997;74:37-40.

14 Levitt NS, Stein K, De Wet T, et al. An inverse relation between blood pressure and birth weight among 5 year old children from Soweto, South Africa. $\mathcal{F}$ Epidemiol Community Health 1999;53:264-8.

15 Hales CN, Barker DJP. Type 2 (non-insulin-dependent) diabetes mellitus: the thrifty phenotype hypothesis. Diabetologia 1992;35:595-601.

16 Phillips DIW, Barker DJP, Hales CN, et al. Thinness at birth and insulin resistance in adult life. Diabetologia 1994;37: and insuli $150-4$.

17 Thomas F, Balkau B, Vauzelle-Kervroedan F, et al and the Codiab-Inserm-Zenesa Study Group. Maternal effect and familial aggregation in NIDDM. The CODIAB Study. Diabetes 1994;43:63-7.

18 Cheta D, Dimtrescu C, Georgescu M, et al. A study on the types of diabetes mellitus in first degree relatives of diabetic patients. Diabete Metab 1990;16:11-15.

19 Keen H, Jarret RJ, McCartney P. The ten year follow up of the Bedford survey (1962-1972): glucose tolerance and diabetes. Diabetologia 1982;22:73-8.

20 Klein B, Klein R, Moss S, et al. Parental history of diabetes in a population based study. Diabetes Care 1996;19:827-30.

21 Pettitt DJ, Aleck KA, Baird HR, et al. Congenital susceptibility to NIDDM: role of intrauterine environment. susceptibility to NIDDM:
Diabetes $1986 ; 37: 622-8$.

22 Alcolando JC, Alcolando R. Importance of maternal history of non-insulin dependent diabetic patients. BMF 1991;302: $1178-80$.

23 Mitchell BD, Kammerer CM, Reinhart LJ, et al. Is there an excess in maternal transmission of NIDDM. Diabetologia 1995;38:314-17.

24 Statistics South Africa. The people of South Africa, population census, 1996. Census in brief. Report No 1. Pretoria: Statistics South Africa, 1998. 